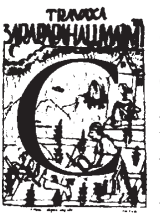
elebramos en estos días las Bodas de Oro de nuestra Universidad, casa donde, como muchos de ustedes, tuve la suerte y el privilegio de obtener mi formación fundamental humana e intelectual, y a la cual me encuentro ligada no solo en lo profesional y académico, sino, sobre todo, en lo afectivo. No deseo, pues -no podría, en realidad-, ocultar la emoción y la alegría con que vengo a decirles estas palabras, con las cuales deseo, a la vez que reafirmar el rumbo de nuestra institución, propiciar una memoria compartida de todo aquello que hemos logrado juntos como comunidad en esta media centuria, y que constituye, sin duda, motivo de justificado orgullo para cada uno de nosotros.

No creo que incurramos en vana presunción si decimos que, al cabo del tiempo transcurrido, hemos construido una gran obra sobre los sólidos cimientos que nos dejaron nuestros fundadores, Honorio Delgado, Alberto Hurtado, Carlos Monge C., Víctor Alzamora C., Hernán Torres, Fernando Porturas, Leopoldo Chiappo, Javier Mariátegui, Javier Arias-Stella, Uriel García, Mariano Querol, solo por mencionar a algunos, promoviendo la excelencia como sinónimo de nuestro trabajo, haciendo que el saber sea un puente para el desarrollo, buscando ofrecer aportes valiosos y duraderos que contribuyan a solucionar los múltiples problemas de nuestra sociedad.

Han sido muchos y muy variados los horizontes hacia los cuales se han dirigido nuestros esfuerzos y en los que, en efecto, hemos cosechado frutos valiosos. Sería, por supuesto, imposible referirme aquí a todos ellos. Por ello me gustaría reseñar solo algunas cifras y datos que dan cuenta de los logros que hemos alcanzado.

En estos 50 años, el número de nuestros alumnos aumentó de poco menos de 500, que teníamos en

* Discurso de la Dra. Fabiola León-Velarde, Rectora de la UPCH, en la Ceremonia central de la celebración de los 50 años de la fundación de la Universidad. la década del 60 con solo tres facultades, Medicina, Ciencias y Estomatología, a lo algo más de 6,000 con los que hoy contamos distribuidos en ocho facultades, las tres iniciales más las Facultades de Psicología, Enfermería, Educación, Salud Pública y Administración y Veterinaria. Este hecho implicó un crecimiento importante de nuestra infraestructura que, ahora cuenta con tres Campus Norte, en San Martín de Porres, nuestro local central, el Campus Sur en Miraflores, futuro Centro Científico Cultural de Miraflores y el Campus Este, en La Molina destinado a los primeros años de estudio. Además, poseemos cuatro clínicas, la Médica y la Veterinaria en San Martín de Porres, y las dos Odontológicas en San Isidro y Lince, así como locales en otras regiones fuera de Lima, el Laboratorio de Investigaciones de Altura en Cerro de Pasco, el Centro de Salud Global en Tumbes, y el nuevo local del IMT en Cusco. Estas instalaciones están construidas en más de 75,000 metros cuadrados de terreno, que se suman a las 100 hectáreas donadas por el distrito de Santa María del Mar. Una sétima parte del área construida de estos terrenos se han destinado a laboratorios y unidades de investigación, entre los cuales los Laboratorios de Investigación y Desarrollo de la Facultad de Ciencias cuenta con la tecnología más avanzada del país. Entre las edificaciones levantadas en los últimos años destacan, los edificios de las Facultades de Veterinaria y Educación, el Centro de Esparcimiento "Enrique Fernández", y nuestro nuevo Campus en La Molina, que fueron construidos todos, durante la gestión del Dr. Oswaldo Zegarra, quien visionariamente apostó por el crecimiento de la universidad y la modernización de su gestión y por la acreditación internacional.

En el pregrado, además de contar con ocho facultades y 14 carreras, hemos logrado sumar 82 especialidades, mientras que en el posgrado ofrecemos a la fecha 43 maestrías y siete doctorados, donde el binomio posgrado-investigación es indisoluble.

El desarrollo de la investigación ha sido siempre una de nuestras preocupaciones permanentes, pues en este tiempo, además del continuo trabajo que rea- 
lizan profesores y alumnos en nuestros 61 laboratorios y unidades de investigación, se han fundado seis centros, entre los que destacan el Centro Editorial, el Centro para la Sostenibilidad Ambiental y el Centro de Salud Global, así como tres institutos especializados, el IMT, el IIA y el IGERO. Esta adecuada infraestructura y esfuerzo permanente, se ha visto recompensada con numerosos reconocimientos por ser la universidad peruana con más investigaciones publicadas en revistas internacionales; así como la universidad latinoamericana en segundo lugar en producción científica publicada en revistas alto impacto, según consta en el informe del grupo de investigación bibliográfica Scimago que dirige el Dr. Félix Moya. Estos logros se encuentran refrendados con la acreditación internacional, con mención en investigación que obtuvimos en el año 2010. Nadie encarna mejor el compromiso con el saber científico de esta casa de estudios que nuestro ex rector, Dr. Alberto Cazorla, quien nos señala el camino a transitar, tan solo con su presencia.

Se ha dado siempre un especial impulso al perfeccionamiento de nuestros docentes, quienes se encuentran entre los más reconocidos del país, y nos permite contar con la plana docente con el más alto grado de perfeccionamiento, $46 \%$ con el grado de Maestro y $24 \%$ con el grado de Doctor.

En el campo de las relaciones inter-institucionales, hemos celebrado más de 400 convenios, que se encuentran vigentes y ejecutándose con universidades de reconocido prestigio, de los cuales 173 son con instituciones extranjeras. Entre éstos cabe resaltar los convenios con Instituciones como la Universidad de Johns Hopkins, la Universidad de Washington, la Fundación Bill y Melinda Gates, la Wellcome Trust, así como la Cooperación Francesa y la Cooperación Belga. Estas importantes alianzas permiten que casi un tercio de nuestro presupuesto se destine a investigación, lo que se ha dado en llamar "El Modelo Cayetano"; al que han aportado además con gran generosidad, nuestro querido benefactor, y ex alum- no, el Dr. Francisco Tejada, así como el Peruvian American Endowment, integrado por ex alumnos de nuestra universidad, hoy exitosos profesionales.

Son, pues, numerosas las tareas proyectadas y llevadas a buen término en estos años. Y si por un lado cabe congratularnos por esos logros colectivos, que hubieran sido imposibles sin la dedicación y la excelencia de todos los miembros de nuestra comunidad -ustedes y quienes nos precedieron-, por otra parte, es imperativo preguntarnos por el sentido más profundo de todo cuanto hemos aprendido y obrado.

Bien sabemos que nuestra Universidad tuvo su origen en la decisión que tomaron un grupo de más de 400 profesores de seguir un camino propio y autónomo. Su determinación -muy excepcional en la historia de las universidades del mundo- supuso grandes esfuerzos, privaciones, sacrificios que fueron más allá de lo profesional y tocaron lo personal, pues todos debieron solicitar préstamos, hacer aportaciones propias y soportar la difícil situación de quedarse sin salario. Este espíritu permeó a todos los docentes de las primeras décadas que aportaron su tiempo y dedicación a la UPCH, sin pensar en posiciones o retribución económica. En este momento de especial dificultad el Patronato, conformado por destacadas personalidades del mundo empresarial, jugó un rol decisivo para hacer posible el surgimiento de la nueva Universidad. Rindo a todos ellos homenaje, y a quienes colaboraron con el Patronato en la persona de su primer presidente, hoy fallecido, Don Enrique Ayulo Pardo.

El objetivo que se habían propuesto estos hombres y mujeres era muy claro: preservar la calidad académica ante el establecimiento de reformas estatutarias que le hacían peligrar. Tenían la convicción de que el saber, para ser pleno y por tanto verdaderamente útil, no debía consentir limitaciones ni obedecer a consignas de ningún tipo, ni políticas, ni ideológicas, ni religiosas. Debía más bien, ser libre, abierto a explorar nuevos horizontes, condición indispensable no solo para el cultivo de cualquier disciplina, 
sino para poder hacer en ella contribuciones que sean realmente importantes y perdurables. Ese saber debía, asimismo, no limitarse al plano intelectual, sino integrar cualidades personales como la honestidad, el sentido de la responsabilidad y la disposición para el diálogo.

Así lo entendieron nuestros fundadores y así lo entendemos hoy quienes recibimos su legado. Por ello hemos buscado hacer de nuestra institución un lugar especialmente propicio para la investigación y la reflexión, donde se cultive el conocimiento con todos los recursos necesarios. Pero, lo que hemos edificado no es un espacio amurallado, alejado del "mundanal ruido", ni una torre de marfil. Por el contrario, hemos sido siempre conscientes de que una verdadera universidad, echa sus raíces sobre la sociedad que la alberga y a la cual debe servir. Allí debemos encontrar por lo pronto la razón por la cual insistimos, en todos los ámbitos de nuestro quehacer, en desarrollar un saber que sea a la vez suficiente, responsable y comprometido con el Perú. Allí debemos encontrar, finalmente, la razón por la cual aquellos que se formaron en nuestras aulas no solo sobresalen por la excelencia en su labor profesional, sino por su sensibilidad social y ciudadana. Roger Guerra-García, nuestro ex Rector, investigador, maestro y político, es un gran representante de varias connotadas figuras Heredianas, que como Honorio Delgado, encontraron perfecta complementariedad entre su labor universitaria y la política.

El sentido comunitario, es otro de los grandes valores que está en la base del origen de nuestra institución y que hemos incorporado como un sello distintivo. Una universidad es, por definición, una comunidad de personas dedicadas a la enseñanza, la difusión y la creación de conocimientos. En nuestro caso, esa condición primera de hace aún más patente, pues sin duda una sólida unión de voluntades, sin un sentimiento colectivo y solidario, no hubiera sido posible hacer realidad el sueño de nuestros fundadores. Por ello, una de nuestras principales preocupaciones ha sido y es mantener vivo, en cada uno de los miembros de nuestra Casa de Estudios, ese espíritu de pertenencia que va más allá de los vínculos formales o el respeto de pactos o reglamentos.

En efecto, pertenecemos a la comunidad Herediana no porque así lo establezcan nuestras leyes y estatutos, sino porque compartimos los mismos ideales, los mismos objetivos, las mismas ilusiones, lo cual hace que nos sintamos identificados y comprometidos con nuestra misión. Esto que menciono se revela con nitidez en el orgullo con que estudiantes y egresados de nuestra Universidad señalan que son Heredianos, pero también en la entrega permanente y desprendida, muchas veces silenciosa, que los profesores y el personal administrativo realizan, desde sus respectivos espacios de trabajo, en el cumplimiento de los objetivos institucionales.

Así pues, hoy que evocamos el acto fundacional y rememoramos el camino recorrido desde entonces, nos toca reconocernos y reafirmarnos en los grandes principios de nuestra institución. Nuestra búsqueda constante de la excelencia académica, nuestro compromiso constante con el desarrollo del saber en su sentido más pleno, y nuestra conciencia de que formamos parte de una gran comunidad, a la que han contribuido con su trabajo numerosas generaciones de maestros, científicos y estudiantes, son, en buena cuenta, los fundamentos que dieron ayer sustancia a nuestra existencia y que hoy animan nuestros anhelos y proyectos.

En representación de todos los que han hecho posible estos 50 años de logros, quiero rendir homenaje a quienes me antecedieron en la conducción de la Universidad, y que hoy no se encuentran con nosotros. A los Dres. y ex Rectores, Carlos Vidal, quien nos ha hecho llegar un cariñoso saludo desde Washington, y se ha excusado por no poder estar con nosotros, y a quienes ya partieron: Honorio Delgado, Alberto Hurtado, Carlos Monge, Enrique Fernández y Homero Silva. 


\section{Queridos Amigos:}

Es innegable que las palabras tienen una preciosa virtud: nos liberan de la prisión del tiempo presente y nos permiten regresar al pasado, a la experiencia vivida, para hallarle sentido y recuperarla definitivamente. Es lo que he intentado hacer: explicitar nuestros afanes y logros a lo largo estos cincuenta años de historia.

Y sin embargo, así como nos abre las puertas al pasado, el lenguaje nos permite también prever y enunciar el futuro, concebir una visión, dar forma definida y reconocible a nuestras ilusiones y, en última instancia, proponer y proponernos una guía para nuestras acciones.

Así, quisiera que me concedan la posibilidad de describirles la Universidad que imagino para cuando cumplamos cien años y por la cual nuestra comunidad, todos ustedes, ha de seguir desplegando, estoy segura, su más vivo esfuerzo.

Una universidad que consolide aún más la integración de todas las voluntades y en la que cada uno de sus miembros se sienta parte de su historia; una universidad que siga siendo cada vez más plural e inclusiva, y que siga convocando a las mentes más resueltas y a los corazones más generosos; una universidad dispuesta a enfrentar con inteligencia los desafíos de su tiempo, a abrirse al mundo moderno para entender a la humanidad de hoy, sin renunciar a su deber ser, que no es otro que el de ser casa de formación; una universidad que destaque en la comunidad mundial no solo por la calidad de su enseñanza, sino por la importancia de sus investigaciones; una universidad donde convivan aún más armoniosamente la ciencia y la ética; una universidad que ofrezca más y mejor ayuda al Perú en su constante búsqueda del desarrollo; una universidad, en fin, con más promesas, con más anhelos, aún más decidida en su compromiso de transformar la realidad y construir una Patria donde no haya cabida para la injusticia, la violencia, la pobreza o alguna forma de discriminación.

Con esta enorme esperanza, que sospecho es compartida por todos nosotros, me gustaría que, como una forma de reiterar nuestro compromiso de identificación con los valores que nos distinguen, nos unamos en un gran y caluroso aplauso por estos 50 años de historia y por al venturoso porvenir de la Universidad Peruana Cayetano Heredia.

Muchas Gracias! 